\title{
Fetal loss rates after mid-trimester amniocentesis
}

\author{
Ilker Arikan, Muge Harma, Aykut Barut, Mehmet Ibrahim Harma, Ulku Bayar
}

Department of Gynecology and Obstetrics, Faculty of Medicine, Zonguldak Karaelmas University, Zonguldak, Turkey; driarikan@hotmail.com, ilkeristanbul@mynet.com

Received 15 December 2009; revised 10 January 2010; accepted 15 January 2010.

\begin{abstract}
Objective: Amniocentesis is an invasive cytogenic test traditionally associated with a $1 / 200$ procedure-related pregnancy loss rate. Recent studies have questioned the validity of the traditionally stated rate. The purpose of this study was to document the results of second-trimester genetic amniocentesis performed at our perinatalogy clinic. Study Design: A retrospective review of all the amniocentesis procedures performed between 15 and 22 weeks of gestation on singleton pregnancies between May 2004 and December 2008 was performed. Spontaneous loss was defined as any unintentional pregnancy loss at < 24 weeks of gestation. Setting: Zonguldak Karaelmas University, Faculty of Medicine, Department of Obstetrics and Gynecology. Population: Pregnant women followed at the Obstetrics Department. Methods: A retrospective review of all the amniocentesis procedures performed between May 2004 and December 2008 was performed. Main outcome measure: Pregnancy loss due to amniocentesis. Results: A total of 447 amniocentesis procedures were performed during the study period. The major indication for amniocentesis was positive maternal triple screening (44\%). The mean gestational age at amniocentesis was $18.80 \pm 2.70$ weeks. The results of cytogenetic analyses revealed an abnormal karyotype in 19 pregnancies $(4.3 \%)$, nine of which were trisomy 21. The overall spontaneous loss rate was $0.89 \%(n=4)$. Conclusion: It would be useful for each center to investigate its own pregnancy loss rate and thereby provide a firmer basis for its policy for counseling women requesting amniocentesis. If enough such investigations were reported, a true benchmark figure could also emerge.
\end{abstract}

Keywords: Genetic Amniocentesis; Mid-Trimester Amniocentesis; Pregnancy Loss; AmniocentesisRelated Fetal Loss

\section{INTRODUCTION}

Amniocentesis was first performed in the 1880 s for decompression of polyhydroamnios. In the $1950 \mathrm{~s}$, amniocentesis for fetal chromosome analysis was initiated as laboratory techniques for cell culture and karyotype were developed. The first reported applications were limited to fetal sex determination. The feasibility of culturing and karyotyping amniotic fluid cells was demonstrated in 1966, and the first prenatal diagnosis of a karyotype was reported in 1967 [1].

Prenatal diagnosis of fetal chromosomal abnormalities is the most common indication for invasive prenatal testing. The prevalence of chromosomal abnormalities in clinically recognized early pregnancy loss is greater than $50 \%$. Fetuses with aneuploidy account for $6-11 \%$ of all stillbirths and neonatal deaths. Chromosomal abnormalities that are compatible with life but cause considerable morbidity occur in $0.65 \%$ of newborns [2].

There are many strategies available to screen for chromosomal abnormalities, including combined test, triple test, quad test, integrated screen, stepwise sequential screen and contingent sequential screen [3]. All of these approaches provide an adjusted risk for Down syndrome and trisomy 18 , but they do not exclude the possibility of an affected fetus, because the test sensitivity is less than $100 \%$. Therefore, amniocentesis is still the only diagnostic test in current use that is valid for diagnosis.

Amniocentesis is an invasive cytogenic test traditionally associated with a $1 / 200$ procedure-related pregnancy loss rate [4]. This risk was initially determined based on data from studies conducted in the 1970s [5] and limited the use of amniocentesis to clinically indicated high-risk populations rather than to all pregnancies.

Recent studies have questioned the validity of this traditionally stated fetal loss rate. For example, Eddleman et al. reported a 1/1600 procedure-related pregnancy loss rate after amniocentesis [6], while Odibo et al. documented a 1/769 amniocentesis-related fetal loss rate in a large single center cohort [7]. 
The purpose of this study was to document the results of the second-trimester genetic amniocenteses we performed and provide a further comparison.

\section{MATERIAL AND METHODS}

A retrospective review of our mid-trimester amniocentesis database for the period from May 2004 to December 2008 was carried out, with all of the amniocentesis procedures performed between 15 and 22 weeks of gestation on singleton pregnancies analyzed, and data on perinatal outcomes gathered from the hospital patient database. Spontaneous loss was defined as any unintentional pregnancy loss at $<24$ weeks of gestation. Elective termination of pregnancy was not considered as pregnancy loss in this analysis.

\section{RESULTS}

A total of 447 amniocentesis specimens were processed during the study period. The mean $( \pm \mathrm{SD})$ maternal age was $31.82 \pm 6.30$ years. The major indications for amniocentesis were positive maternal triple screening (44\%), advanced maternal age with positive maternal triple screening (18.9\%) and advanced maternal age solely $(15.5 \%)$ (Table 1). The mean $( \pm \mathrm{SD})$ gestational age at amniocentesis was $18.80 \pm 2.70$ weeks. The mean $( \pm \mathrm{SD})$ gestational age at delivery was $38.06 \pm 2.44$, and the mean $( \pm \mathrm{SD})$ birthweight was $3261.30 \pm 850.40 \mathrm{~g}$.

Cytogenetic analysis revealed an abnormal karyotype in 19 pregnancies $(4.3 \%)$, nine of them being trisomy 21 (Table 2).

The overall spontaneous loss rate at less than 24 weeks of gestation was $0.89 \%(n=4)$, and 41 preterm deliveries $(9.2 \%)$ before 37 weeks of gestation occurred. Fifteen (3.4\%) patients experienced preeclampsia. The rate of low birthweight $(<2500 \mathrm{~g})$ infants was $8.6 \%$ (Table 3).

Table 1. Indications for amniocentesis.

\begin{tabular}{lcc}
\hline Indication & n & \% \\
\hline Positive maternal serum triple screening & 196 & 43.8 \\
Positive maternal combined screening & 42 & 9.4 \\
$\begin{array}{l}\text { Advanced maternal age ( } \geq 35 y) \\
\text { Positive maternal serum triple screening }+\end{array}$ & 69 & 15.4 \\
$\begin{array}{l}\text { Positive maternal combined screening } \\
\text { Positive maternal serum triple screening }+\end{array}$ & 84 & 1.8 \\
$\begin{array}{l}\text { Advanced maternal age }(\geq 35 y) \\
\text { Positive maternal combined screening }+\end{array}$ & 4 & 0.9 \\
$\begin{array}{l}\text { Advanced maternal age ( } \geq 35 y) \\
\text { Others* }\end{array}$ & 44 & 9.8 \\
\hline
\end{tabular}

* Previous child with chromosomal abnormality, previous fetus with malformation and unknown karyotype, thickened nuchal translucency at 11-14 wk of gestation, two soft markers for aneuploidy on genetic sonogram, parental anxiety.
Table 2. Results of cytogenetic analyses.

\begin{tabular}{|c|c|c|c|c|c|c|}
\hline \multirow[b]{2}{*}{ Results } & \multirow[b]{2}{*}{$\mathbf{n}$} & \multirow[b]{2}{*}{$\%$} & \multicolumn{4}{|c|}{ Indication for amniocentesis } \\
\hline & & & $\begin{array}{c}\text { PM } \\
\text { S }\end{array}$ & $\begin{array}{l}\text { A } \\
\mathbf{M} \\
\mathbf{A}\end{array}$ & $\begin{array}{l}\text { PMS+ } \\
\text { AMA }\end{array}$ & $\begin{array}{c}\text { Oth } \\
\text { er }\end{array}$ \\
\hline $\begin{array}{c}\text { Culture fail- } \\
\text { ure }\end{array}$ & 5 & 1.1 & & & & \\
\hline $\begin{array}{l}\text { Successful cell } \\
\text { culture }\end{array}$ & 442 & 98.9 & & & & \\
\hline $\begin{array}{c}\text { Normal } \\
\text { karyotype }\end{array}$ & 423 & 94.7 & & & & \\
\hline $46, \mathrm{XX}$ & 205 & 48.4 & & & & \\
\hline $46, X Y$ & 218 & 51.6 & & & & \\
\hline $\begin{array}{l}\text { Cytogenetic } \\
\text { abnormality }\end{array}$ & 19 & 4.3 & & & & \\
\hline Trisomy 21 & 9 & & 2 & 3 & 3 & 1 \\
\hline Trisomy 18 & 2 & & 1 & - & 1 & - \\
\hline $47 \mathrm{XXY}$ & 1 & & - & 1 & - & - \\
\hline $48 \mathrm{XXXX}$ & 1 & & 1 & - & - & - \\
\hline $\begin{array}{c}47 \mathrm{XX} \\
\text { t21(16\%) }\end{array}$ & 1 & & - & - & 1 & - \\
\hline $\begin{array}{c}46 \mathrm{XX} \text { inv (9) } \\
(\mathrm{p} 11 \mathrm{q} 13)\end{array}$ & 5 & & 2 & 1 & - & 2 \\
\hline
\end{tabular}

PMS, positive maternal serum screening (combined or triple); AMA, advanced maternal age ( $\geq 35 \mathrm{y})$;

Other, previous child with chromosomal abnormality, previous fetus with malformation and unknown karyotype, thickened nuchal translucency at 11-14 wk of gestation, two soft markers for aneuploidy on genetic sonogram, parental anxiety.

Table 3. Pregnancy outcomes.

\begin{tabular}{lcc}
\hline Outcome & $\mathrm{n}$ & $\%$ \\
\hline Fetal loss less than $24 \mathrm{wk}$ & 4 & 0.89 \\
Preterm delivery $(<37 \mathrm{wk})$ & 41 & 9.2 \\
Low Birth Weight infant $(<2500 \mathrm{~g})$ & 38 & 8.6 \\
Preeclampsia-eclampsia & 15 & 3.4 \\
\hline
\end{tabular}

\section{DISCUSSION}

Unintended pregnancy loss has been the major concern with amniocentesis over the past four decades. The traditional estimated loss rate of 1 in 200, which was derived from the studies conducted in the 1970 s, is based on recommendations by the Centers for Disease Control and Prevention and endorsed by the American College of Obstetricians and Gynecologists (ACOG) $[4,8]$.

Recent studies have reported lower fetal loss rates and have criticized the studies conducted in 1970s because they were not randomized [6,7] (though Eddelmann [6] admitted that further randomized prospective trials could not now be performed because of ethical considerations) and were not performed under concurrent ultrasound guidance [6]. However, the figure of 1 in 1600 reported by Eddlemann et al. [6] in 2006 has been criticized by most investigators [9-11]. The only randomized study evaluating pregnancy loss rates, published by Tabor et al. in 1986 , reported a procedure-related loss rate of $1 \%$ 
[12], while a recent review by Seeds reported a loss rate of $0.6 \%$ [13].

In 2007, ACOG changed its 2001 recommendations, quoting the procedure-related loss rate after midtrimester amniocentesis as less than 1 in 300-500 [14]. The figure of $0.89 \%$ obtained in our study (Table 3 ) is close to the $1 \%$ obtained by Eddleman et al. [6] and the $0.97 \%$ of Odibo et al. [7]. Our rate of $9.2 \%$ preterm $(<37$ weeks gestation) deliveries is less than the $11 \%$ preterm birth rate for singletons in the USA in 2005 , while our $8.6 \%$ rate for low birthweight infants is similar to the 2005 US figure for singletons (7.55\%) [15].

Although this study is limited by its retrospective design, its lack of a control group, and the small numbers involved, its findings agree with other recent reports. It would be useful if other centers similarly investigated and reported their own pregnancy loss rates associated with amniocentesis, and perhaps used their results to reexamine their policies for counseling women requesting amniocentesis.

\section{REFERENCES}

[1] Jenkins, T.M. and Wapner, R.J. (2004) Prenatal diagnosis of congenital disorders. In Creasy, R.K., Resnik, R. and Iams, J. Eds. Maternal-Fetal Medicine Principles and Practice. 5th Edtion, Philadelphia, WB Saunders, 235-280.

[2] American College of Obstetricians and Gynecologists. (2007) Invasive prenatal testing for aneuploidy. ACOG Practice Bulletin No. 88, Obstetrics \& Gynecolgy, 110, 1459-1467.

[3] Rappaport, V.J. (2008) Prenatal diagnosis and genetic screening-integration into prenatal care. Obstetrics \& Gynecology Clinics of North America, 35, 3.

[4] Centers for Disease Control and Prevention. (1995) Chorionic villus sampling and amniocentesis: Recommendations for prenatal counseling. MMWR Recommendations and Reports, 44, 1-12.
[5] Bornstein, E., Lenchner, E., Donnenfeld, A., Barnhard, Y., Seubert, D. and Divon, M. (2009) Advanced maternal age as a sole indication for genetic amniocentesis; risk-benefit analysis based on a large database reflecting the current common practice. Journal of Perinatal Medicine, 37, 99-102.

[6] Eddleman, K.A., Malone, F.D., Sullivan, L. et al. (2006) Pregnancy loss rates after midtrimester amniocentesis. Obstetrics \& Gynecology, 108, 1067-1072.

[7] Odibo, A.O., Gray, D.L., Dicke, J.M., Stamilio, D.M., Macones, G.A. and Crane, J.P. (2008) Revisiting the fetal loss rate after second-trimester genetic amniocentesis: A single center's 16-year experience. Obstetrics \& Gynecology, 111, 589-595.

[8] American College of Obstetricians and Gynecologists. (2001) Prenatal diagnosis of fetal chromosomal abnormalities. ACOG Practice Bulletin, Washington (DC), ACOG, 27.

[9] Nicolaides, K. (2007) Pregnancy loss rates after midtrimester amniocentesis. Obstetrics \& Gynecology, 109(3), 780.

[10] Wapner, R.J., Evans, M.I. and Platt, L.D. (2007) Pregnancy loss rates after midtrimester amniocentesis. $\mathrm{Ob}$ stetrics \& Gynecology, 109(3), 780.

[11] Alfrevic, Z. and Tabor, A. (2007) Pregnancy loss rates after midtrimester amniocentesis. Obstetrics \& Gynecology, 109(5), 1203-1204.

[12] Tabor, A., Philip, J., Madsen, M., Bang, J., Obel, E.B. and Norgard-Pedersen, B. (1986) Randomized controlled trial of genetic amniocentesis in 4606 low-risk women. Lancet, 1, 1287-1293.

[13] Seeds, J.W. (2004) Diagnostic mid trimester amniocentesis: how safe? American Journal of Obstetrics \& Gynecology, 191, 607-616.

[14] American College of Obstetricians and Gynecologists. (2007) Invasive prenatal testing for aneuploidy. ACOG Practice Bulletin No. 88, Obstetrics \& Gynecolgy, 110, 1459-1467.

[15] Martin, J.A., Hamilton, B.E., Sutton, P.D, et al. (2007) Births: Final data for 2005. National Vital Statistics Reports, 56, 6 . 